\title{
Spatiotemporal changes of vegetation on the Tibetan Plateau and relationship to climatic variables during multiyear periods from 1982-2012
}

\author{
Jiaqiang Du ${ }^{1,2} \cdot$ Chenxi Zhao $^{2} \cdot J^{\prime a n m i n} \mathrm{Shu}^{1} \cdot$ Ahati Jiaerheng $^{2} \cdot$ Xinjie Yuan $^{2} \cdot$ \\ Junqi Yin ${ }^{2} \cdot$ Shifeng Fang ${ }^{3} \cdot$ Ping $\mathrm{He}^{1,2}$
}

Received: 28 October 2014/Accepted: 14 July 2015/Published online: 21 December 2015

(c) Springer-Verlag Berlin Heidelberg 2015

\begin{abstract}
Understanding the dynamics of vegetation system change is often limited by relatively brief data sequences and the shortage of comparable analyses of variation over longer periods. In this study, GIMMS NDVI and MODIS NDVI datasets were integrated to establish a consistent NDVI time series from 1982 to 2012 on vegetation of the Tibetan Plateau in China. The spatiotemporal patterns of change in seasonal NDVI and their linkage with climatic variables were analyzed at regional and pixel scales over 14 periods ranging from 18 to 31 years and beginning in 1982. On a regional scale, positive trends of growing season and seasonal NDVI were observed during the 14 periods, and the increases were statistically significant for growing season NDVI during all periods, and for summer and autumn NDVI during only the last four and the last two periods, respectively. The rates of NDVI increase in growing season and spring significantly decreased over the 14 periods. NDVI rates slightly decrease in summer and significantly increase in autumn. At a pixel scale, areas with significant greening or significant browning significantly increased over the 14 periods during the growth season and during all seasons except spring, in which the proportion of vegetated area with
\end{abstract}

Jiaqiang Du

dujq@craes.org.cn

1 State Key Laboratory of Environmental Criteria and Risk Assessment, Chinese Research Academy of Environmental Sciences, Beijing 100012, China

2 Xinjiang Academy of Environmental Protection Science, Xinjiang 830011, China

3 State Key Laboratory of Resources and Environmental Information System, Institute of Geographic Sciences and Natural Resources Research, Chinese Academy of Sciences, Beijing 100101, China greening rapidly decreased. Temperature was the primary climatic driver for the observed vegetation changes during multiple periods while precipitation and sunshine duration had significant impacts on vegetation growth only in limited parts of the study area or during spring. Vegetation growth response to climate change varied across seasons and regions. Trend analysis during the multiple nested time series provides a better understanding of NDVI dynamics and may help to forecast future changes. Spring NDVI is likely to continue decreasing, autumn NDVI will continue increasing, and the magnitude of the NDVI increase during growing season will decline in the future.

Keywords GIMMS NDVI - MODIS NDVI - Vegetation dynamics trends $\cdot$ Climate change $\cdot$ Correlation $\cdot$ Multiple periods analysis $\cdot$ Tibetan Plateau

\section{Introduction}

Plants are important primary producers at, or near, the beginning of most food chains. Vegetation provides food and shelter for a variety of organisms and links material circulation and energy flow in the pedosphere, hydrosphere, and atmosphere. Vegetation also plays an important role in the regulation of global carbon balance and the maintenance of climate stability (Peng et al. 2012b; Piao et al. 2011). Monitoring changes in the dynamics of vegetation activity has scientific value and practical significance. Understanding the relationship between the "greenness" of vegetation and climate is an important topic in global change research because it indicates responses of terrestrial ecosystems to climate changes (Goetz et al. 2005; Myneni et al. 1991; Peng et al. 2011). The Normalized Difference Vegetation Index (NDVI) is a 
vegetation index used to measure vegetation greenness and it is one of the best indicators for visualizing temporal changes of vegetation growth. Several studies have demonstrated that the Global Inventory Modeling and Mapping Studies (GIMMS) NDVI dataset performs best in detecting long-term vegetation trends (Beck et al. 2011; Beck and Goetz 2011; Fensholt et al. 2012; Jeong et al. 2011; Peng et al. 2011; Zhao et al. 2011). The most widely used GIMMS NDVI datasets are of the time series from 1981 to 2006. To compare recent vegetation dynamics with historical vegetation dynamics, an extension of the GIMMS NDVI dataset time series is required (de Jong et al. 2011; Mao et al. 2012). Moderate resolution imaging spectroradiometer (MODIS) provides data that are improvements over GIMMS NDVI (Fensholt et al. 2009). MODIS instrumentation enhances spatial resolution and sensitivity to chlorophyll, excludes the interference of atmospheric and water vapor, modifies the synthesis method, and is a continuation and upgrade of GIMMS NDVI (Huete et al. 2002). Studies comparing GIMMS and MODIS NDVI datasets and data interpolation have been conducted in many locations (Brown et al. 2006; Tucker et al. 2005; Chen et al. 2011; Ding et al. 2010; Gallo et al. 2005; He et al. 2012; Mao et al. 2012; Peng et al. 2012a; van Leeuwen et al. 2006).

The Tibetan Plateau (TP) is the highest and largest highland in the world. It has several unique vegetation types and climates. As the 'Third Pole' of the world and the 'Asian water tower,' the TP exerts huge impacts on regional and global climate through thermal and mechanical forcing mechanisms (Duan et al. 2011, 2012a, b; Liu and Wang 2011; Qin et al. 2009; Shichang et al. 2010; Yang et al. 2010). TP ecological processes provide ecological security to China and East Asia (Sun 2012). In recent years, the $\mathrm{TP}$ has experienced substantial climate change, such as pronounced warming (Duan et al. 2011; Qin et al. 2009; Shichang et al. 2010; Yang et al. 2014), reduced wind (Cuo et al. 2012; Yang et al. 2011, 2014;) and reduced precipitation (Huang et al. 2011). The combination of these changes has greatly impacted vegetation growth (Ding et al. 2010; Mao et al. 2007; Mohammat et al. 2013; Peng et al. 2012b; Xu et al. 2011, 2012; Yang et al. 2005; Yang and Piao 2006; Zhang et al. 2010). Linear trend analysis over a long series of years may obscure significant changes appearing within shorter time intervals (de Jong et al. 2012). Comparative analysis of results from multi-periods, changes in vegetation NDVI over the most recent years, and dynamics of NDVI trends are poorly studied. An increase in the number of remote sensors and the combined use of multi-sensor data to monitor current and historical vegetation dynamics will become more common in the future (Shen et al. 2014; van Leeuwen et al. 2006). For these reasons, GIMMS NDVI and MODIS
NDVI data sets were combined in the present study, and these datasets were used to study changes in the TP vegetation over 14 periods: 1982-1999, 1982-2000,..., 1982-2012 using multiple spatial scales and in different seasons. The correlations of vegetation with contemporary temperature, precipitation, and hours of sunshine were also analyzed. The main goals addressed in this study were:

1. Understanding the relationships between the GIMMS and MODIS NDVI and constructing a long-term NDVI time-series covering 1982-2012 by integrating the two datasets for the TP.

2. Determining the spatial and temporal patterns in trends of vegetation greenness on the TP over the period 1982-2012. Are there differences among time periods and between seasons?

3. Identifying the main climatic drivers for the observed vegetation changes on the TP.

\section{Materials and methods}

\section{Studied areas}

The TP is located at southwestern China covering the whole of Tibet and Qinghai provinces, and parts of Xinjiang, Gansu, Sichuan, and Yunnan provinces (Fig. 1). It lies within $26.0^{\circ}-39.8^{\circ} \mathrm{N}$, and $78.3^{\circ}-104.8^{\circ} \mathrm{E}$, and has a size of about one-quarter of the Chinese territory and mean elevation of more than $4000 \mathrm{~m}$ above sea level. Surface elevation changes rapidly across the boundaries of the TP and strong contrasts exist between the western and eastern parts in terms of land surfaces, vegetation, and climate. Combining with the factors such as topography and geographical location, the plateau climate in the study area exhibits a gradient from warm and humid in southeast to cold and dry in northwest, which leads to spatial differentiation of biomes (Peng et al. 2012b). Hydrothermal conditions on the TP at the biological limit level make the terrestrial ecosystem extremely sensitive to climate change. As one of the most sensitive areas to climate change with great ecological vulnerability, the $\mathrm{TP}$ has been recognized as a suitable place for the study on the response of vegetation NDVI to climate change.

\section{Data sources and processing}

The GIMMS NDVI datasets were acquired from the GIMMS group and was derived from the NOAA/AVHRR land datasets with a spatial resolution of $8 \mathrm{~km} \times 8 \mathrm{~km}$ and 15-day interval from 1982 to 2006 . The GIMMS NDVI datasets have been corrected to minimize the effects of 


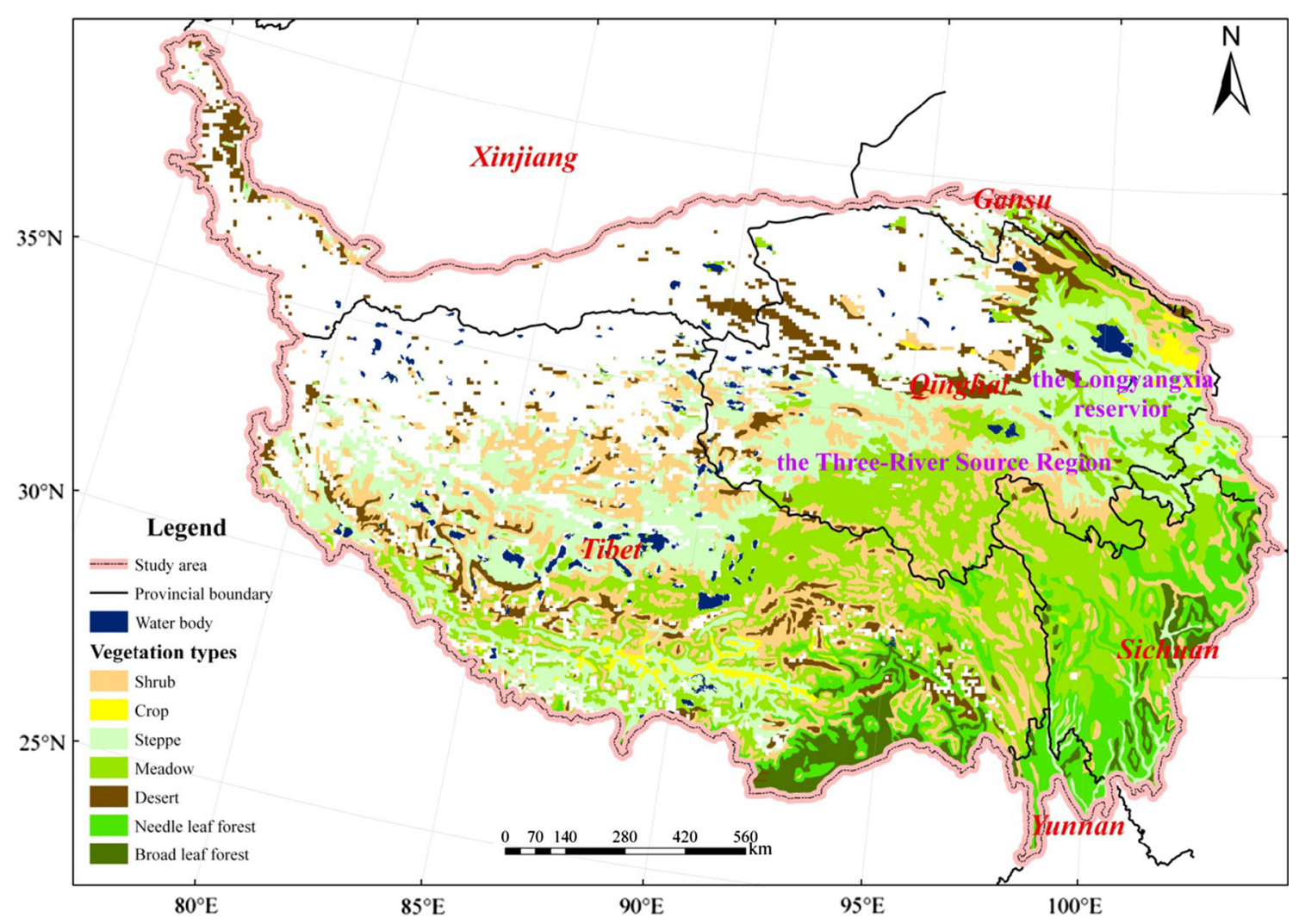

Fig. 1 Distribution of vegetation types and climate stations on the TP

volcanic eruptions, solar angle as well as sensor errors and shifts and thus can be used to evaluate the long-term trends in vegetation activity. The spatial resolution of the MODIS NDVI datasets (MOD13A3) obtained from NASA's Earth Observing System from 2000 to 2012 was $1 \mathrm{~km} \times 1 \mathrm{~km}$. The long-term monthly mean temperature, monthly precipitation and monthly sunshine duration data were acquired from the China Meteorological Data Sharing Service System. The data on vegetation type were digitized from a 1:1,000,000 scale vegetation map (China 2001). Vegetation types were classified as follows: needle leaf forest, broad leaf forest, shrub, steppe, meadow, crop, desert and non-vegetation area. Figure 1 also shows the distribution of different types of vegetation.

The monthly GIMMS NDVI datasets were obtained using the maximum value composite (MVC) method. Using a spatial average resampling method like Fensholt et al. (2009) and Fensholt et al. (2012), the MODIS NDVI was resampled to a spatial resolution of $8 \mathrm{~km} \times 8 \mathrm{~km}$ to be consistent with the GIMMS NDVI datasets. Pixels with a mean growing season NDVI $<0.10$ were excluded in this study to reduce the influence of sparsely vegetated pixels on the NDVI trend following the lead of earlier related research studies (Mohammat et al. 2013; Piao et al. 2011a, b; Zhang et al. 2013; Zhao et al. 2011).

\section{Methods}

The two NDVI datasets were obtained from different remote sensors and spectral bands, spectral response function, and local overpass times were not consistent. There are significant differences between the NDVI value from GIMMS and MODIS, so the GIMMS and MODIS NDVI cannot be directly combined to evaluate the trend of vegetation activity (de Jong et al. 2011; Ding et al. 2010; He et al. 2012; Mao et al. 2012). Checking the continuity and consistency of the two NDVI datasets is necessary before using them together. Using equivalent spatially and temporally overlapping processed monthly GIMMS and MODIS NDVI datasets from 2000 to 2006, a per-pixel unary linear regression model was established. Combining this model and MODIS NDVI data during 2000-2012, simulated GIMMS NDVI data were produced. The monthly GIMMS NDVI dataset and simulated GIMMS NDVI data after 2007 constitutes the NDVI time series of the TP covering 1982-2012. The correlation, difference, and error analyses on the GIMMS and simulated GIMMS NDVI were used to check the accuracy of the simulated GIMMS NDVI data.

The growing season was divided into three segments: spring (April-May), summer (June-August), and autumn 
(September-October). NDVI of the growing season and different seasons were calculated as the mean of the NDVI values for the corresponding months. The method of leastsquares linear regression is characterized by simplicity and robustness (Peng et al. 2012b), and the results are easy to interpret and compare between datasets and between pixels (Fensholt et al. 2009). This statistical technique was therefore used to estimate linear time trends of NDVI and three climate variables (temperature, precipitation and sunshine duration) during given periods at regional and pixel scales, and the significance level $(P)$ of these variables was determined using the $F$ test. Absolute and percent NDVI changes were measured as linear regression slope and the ratio of slope to the mean annual NDVI during 1982-2012 (Yang and Piao 2006).

The Pearson correlation coefficients between NDVI and climate variables during the same period were calculated and it was assumed that interannual variability in NDVI was related to temporal variability in climate variables if the correlation coefficients were statistically significant. Based on climate data at weather stations, the ordinary Kriging method was used to generate a temperature, precipitation, and sunshine duration map with the same resolution and geographic coordinate system as those of the GIMMS NDVI datasets. To analyze the temporal patterns and dynamic processes, trends of NDVI and the correlation between NDVI and climatic factors over progressively longer periods of 18-31 years since 1982 were estimated and the percentage of the area showing a positive or negative trend in the 14 nested time series was calculated. According to the results of the significance test, the trends or correlations were classified into three ranks: highly significant $(P \leq 0.01)$, significant $(P \leq 0.05)$, and not significant $(P>0.05)$.

\section{Results}

\section{Data consistency test}

Figure 2 shows the pixel-by-pixel correlation between monthly GIMMS and MODIS NDVI datasets during 2000-2006. The percentage of area on the TP had a significant positive correlation for $96 \%$ ( $P \leq 0.05), 94 \%$ $(P \leq 0.01)$ of the pixels. Spatial patterns of this type of correlation differed among different areas. The correlation was less significant in the northern non-vegetated area and also in the southwestern broadleaf forest region of the TP.

The mean monthly GIMMS and simulated GIMMS NDVI at a regional scale from February 2000 to December 2006 (Fig. 3a) had a correlation coefficient of 0.9918 $(P<0.001, n=83)$. The slope, intercept, correlation were significantly improved compared to the corresponding values between GIMMS and MODIS (Fig. 3c). The absolute error of GIMMS and simulated GIMMS NDVI was 0.00001 for an average of all pixels and the relative error was $0.005 \%$. The proportion of pixels with difference values between \pm 0.02 to all pixels was $100 \%$ (Fig. 3b). The absolute error, relative error, and \pm 0.02 difference values between GIMMS and MODIS were -0.0256, -14.04 , and $59.15 \%$ (Fig. 3d), respectively.

\section{Vegetation dynamic trends during 14 periods}

\section{Change in vegetation growth at the regional scale}

The growing season NDVI increased significantly $\left(R^{2} \geq 0.18, n=18-31\right)$ during 14 periods, with an annual increase magnitude of $4.25-7.68 \times 10^{-4}(0.21-0.27 \%)$ (Fig. 4a). Significant increases $(P \leq 0.01)$ were found in several periods. The maximum and minimum increase rate of the growing season NDVI occurred in the period of 1982-2002 and in the period of 1982-2011, respectively (Figs. 4a, 5). Spring NDVI showed significant increases $\left(R^{2} \geq 0.23, n=18-19\right)$ during the first two periods and non-significant increases during all other periods at a rate of $0.26-13.71 \times 10^{-4}$ year $^{-1}\left(0.01-0.77 \%\right.$ year $\left.^{-1}\right)$. The largest and smallest increase rates of spring NDVI were found in the first and the last periods, respectively. There were two distinct periods with opposite trends in spring NDVI: it significantly increased $\left(R^{2}=0.36, n=17\right)$ from 1982 to 1998 , and then decreased $\left(R^{2}=0.15, n=15\right.$, $P>0.05$ ) from 1998 to 2012 (Figs. 4b, 5). Statistically significant and non-significant positive trends of summer NDVI were observed during the 1982-2002 period and during the last four periods $\left(R^{2} \geq 0.16, n=21,28-31\right)$, and during all other periods, respectively. The increase rates of summer NDVI during all periods varied between $6.22 \times 10^{-4}$ year $^{-1}\left(0.18 \%\right.$ year $\left.^{-1}\right)$ and $11.93 \times 10^{-4}$ year $^{-1}\left(0.35 \%\right.$ year $\left.^{-1}\right)$ with the maximum in the 1982-2002 period and the minimum in the 1982-2005 period (Figs. 4c, 5). Autumn NDVI on the TP increased by $1.42-4.91 \times 10^{-4}$ year $^{-1}\left(0.05-0.16 \%\right.$ year $\left.^{-1}\right)$ during all periods, with only the last two periods being significant at the 0.05 level $\left(R^{2} \geq 0.14, n=30-31\right.$, Figs. $\left.4 d, 5\right)$. As the NDVI record increases in length, the increase in magnitude high-significantly decreased for growing season and spring ( $R^{2}=0.77, R^{2}=0.81, n=14$, respectively), and highsignificantly increased for autumn $\left(R^{2}=0.64, n=14\right)$, but there was no significant decrease for summer $\left(R^{2}=0.24, n=14\right)$.

\section{Spatial pattern of vegetation growth}

Changes in NDVI are shown in Table 1. More than half of the study area had increasing trends in growing season, 


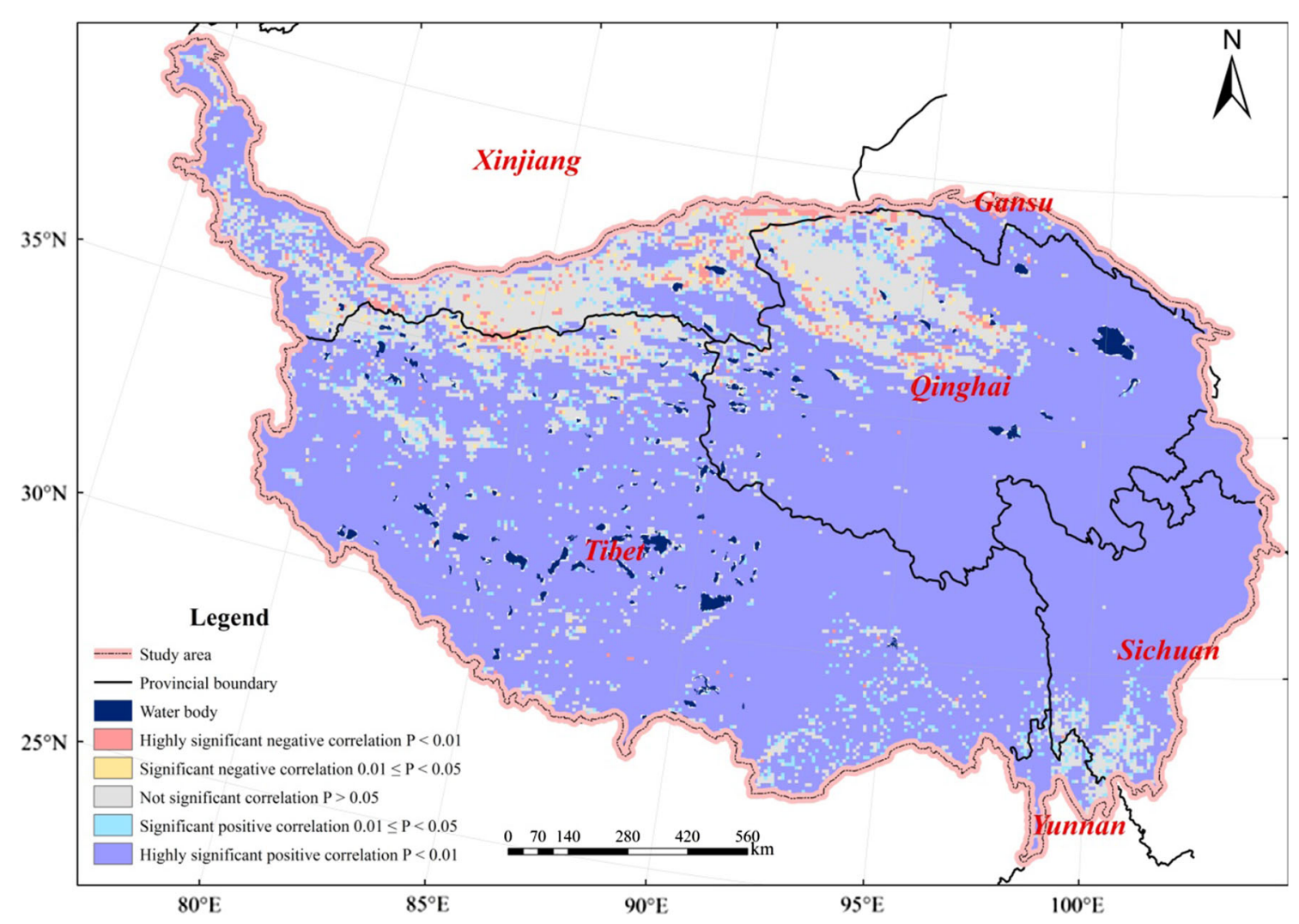

Fig. 2 Correlation relationship between GIMMS and MODIS monthly NDVI during 2000-2006 per pixels

summer, and autumn NDVI during all periods. Pixels also had significantly positive trends more often than significantly negative trends. Spring NDVI increased over $88 \%$ of the study area during 1982-1999 and then declined to $45 \%$ during 1982-2012. Areas with a significant increase in spring NDVI developed from being much more than that with a significant decrease during 1982-1999 to becoming noticeable less than the corresponding during 1982-2012. Areas with non-significant greening during the growing season, spring, and summer decreased over the 14 periods but this trend is statistically significant only for the growing season and spring $\left(R^{2}=0.77, R^{2}=0.90, n=14\right)$, whereas areas with non-significant greening in the autumn slightly increased. Significant browning areas in the growing season and all seasons highly significantly increased $\left(R^{2}=0.97, R^{2}=0.96, R^{2}=0.91, R^{2}=0.91\right.$, $n=14)$ as the period length increased. The significant greening area significantly decreased in spring over the 14 periods. In contrast, highly significant expansions of areas with significant increase in growing season, summer, and autumn $\left(R^{2}=0.83, R^{2}=0.86, R^{2}=0.98, n=14\right)$ were found.

In general, a significant increasing trend in growing season NDVI was found in many parts of the TP, most conspicuously in the east and southwest. Areas with significant decrease were scattered in the central and southeastern TP (Fig. 6). Pixels that displayed significant increase in spring NDVI were distributed in the eastern and southern TP, and the pixels with significant decrease were concentrated in the central TP and scattered in the southeastern TP (Fig. 7). The sign of the NDVI trend during both spring and the growing season for the central TP reversed from being positive during 1982-1999 to becoming significantly negative during 1982-2012 (Figs. 6, 7). For the northeastern and southwestern TP, the majority of pixels were characterized by a significant positive trend in summer NDVI, while for southeastern $\mathrm{TP}$ and the area around the Longyangxia reservoir in Qinghai the trend was significantly negative. Compared to the 1982-2006 period, areas with significant changes in summer NDVI increased in 1982-2012. Areas with a significant increase in autumn NDVI were mainly located in the eastern and southern TP. The sign of the autumn NDVI trend for the Three-River Source Region in Qinghai reversed from being negative during 1982-1999 to becoming positive during 1982-2012, and the opposite change occurred in northern Tibet. 

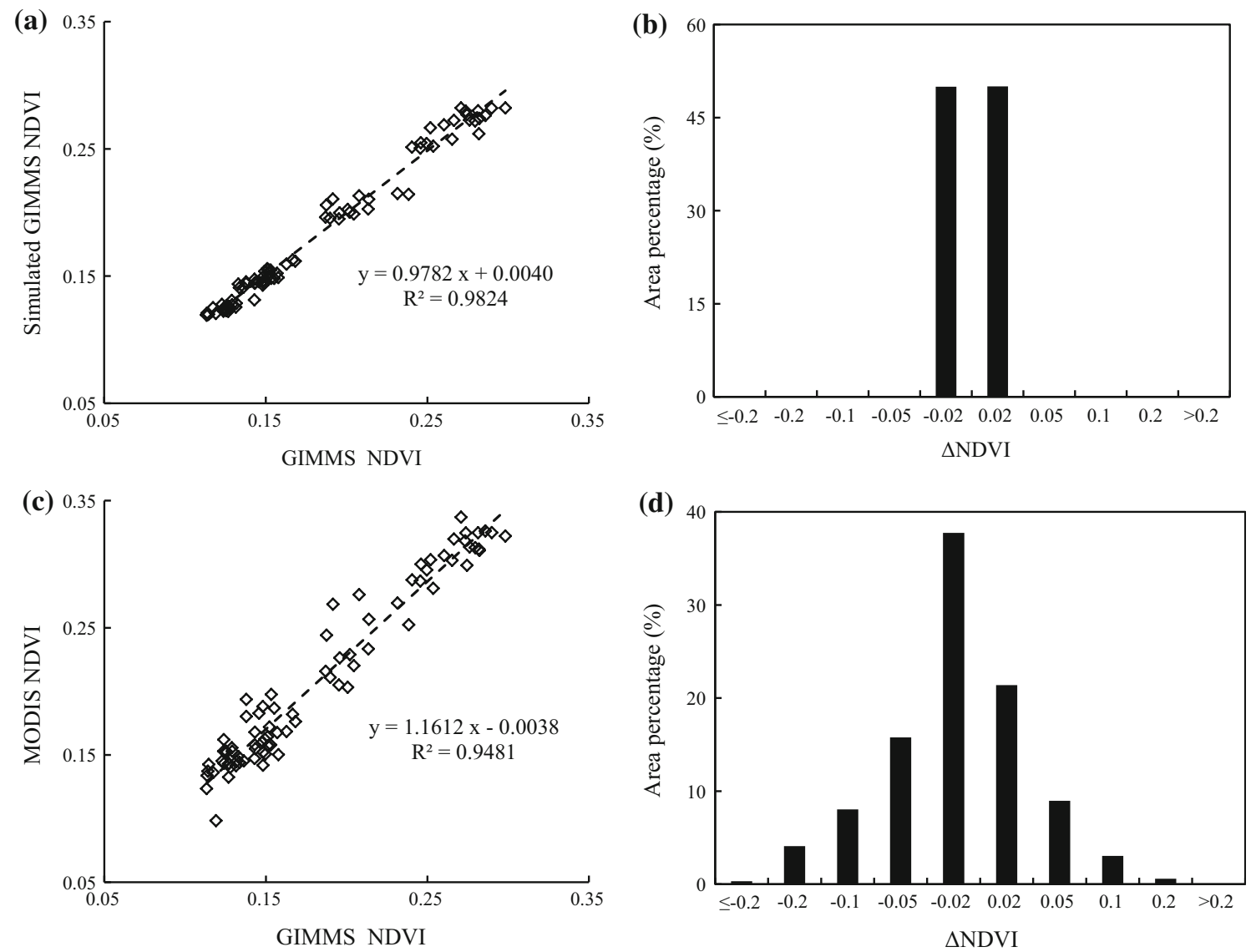

Fig. 3 Consistency analysis of simulated results: a, c spatial mean; b, d difference statistics

\section{Relationships between NDVI and climate variables}

\section{Correlations between NDVI and climate variables in the TP}

At the TP regional scale, there were strong positive correlations between NDVI and temperatures during the growing season, summer, and autumn (Table 2). Most of the correlations during the 14 time periods were significant at the 0.05 level, and increased with increased study time period (from 1982-1999 to 1982-2012). Significant positive correlations between spring NDVI and temperature occurred only during the first few periods. NDVI-precipitation and NDVI-sunshine duration relationships were not significant for growing season, summer, and autumn during all periods, whereas the correlations for spring were relatively strong: reaching a 0.1 significance level for NDVI and precipitation during the last nine periods, and for NDVI and sunshine duration during the last ten periods. For growing season and all seasons during all periods except for spring during the last six periods, correlations between NDVI and temperature were stronger than correlations with precipitation and with sunshine duration (Table 2).
Spatial patterns of interannual correlation between NDVI and climate

The NDVI positively correlated with temperature in more than half of the TP for growing season and all seasons during all periods. Areas with significant positive correlation between NDVI and temperature were more common than those with significant negative correlations (Table 3). For growing season, summer, and autumn, pixels with significant positive correlation between NDVI and temperature increased significantly $\left(R^{2}=0.97, R^{2}=0.98, R^{2}=0.95\right.$, $n=14$ ) as the study period lengthened, but for spring there was a significant decrease $\left(R^{2}=0.84, n=14\right)$. Pixels with significant positive correlation between NDVI and temperature in the growing season and spring were mainly distributed in the eastern and southwestern TP. For the summer they were mainly distributed in the northeastern parts of the TP and for autumn they were mainly distributed in the central TP (Fig. 8). The spring NDVI positively correlated with temperature in the central TP during 1982-1999 and negatively correlated during 1982-2012 (Fig. 8).

For growing season, summer and autumn, pixels with significant positive correlation between NDVI and 

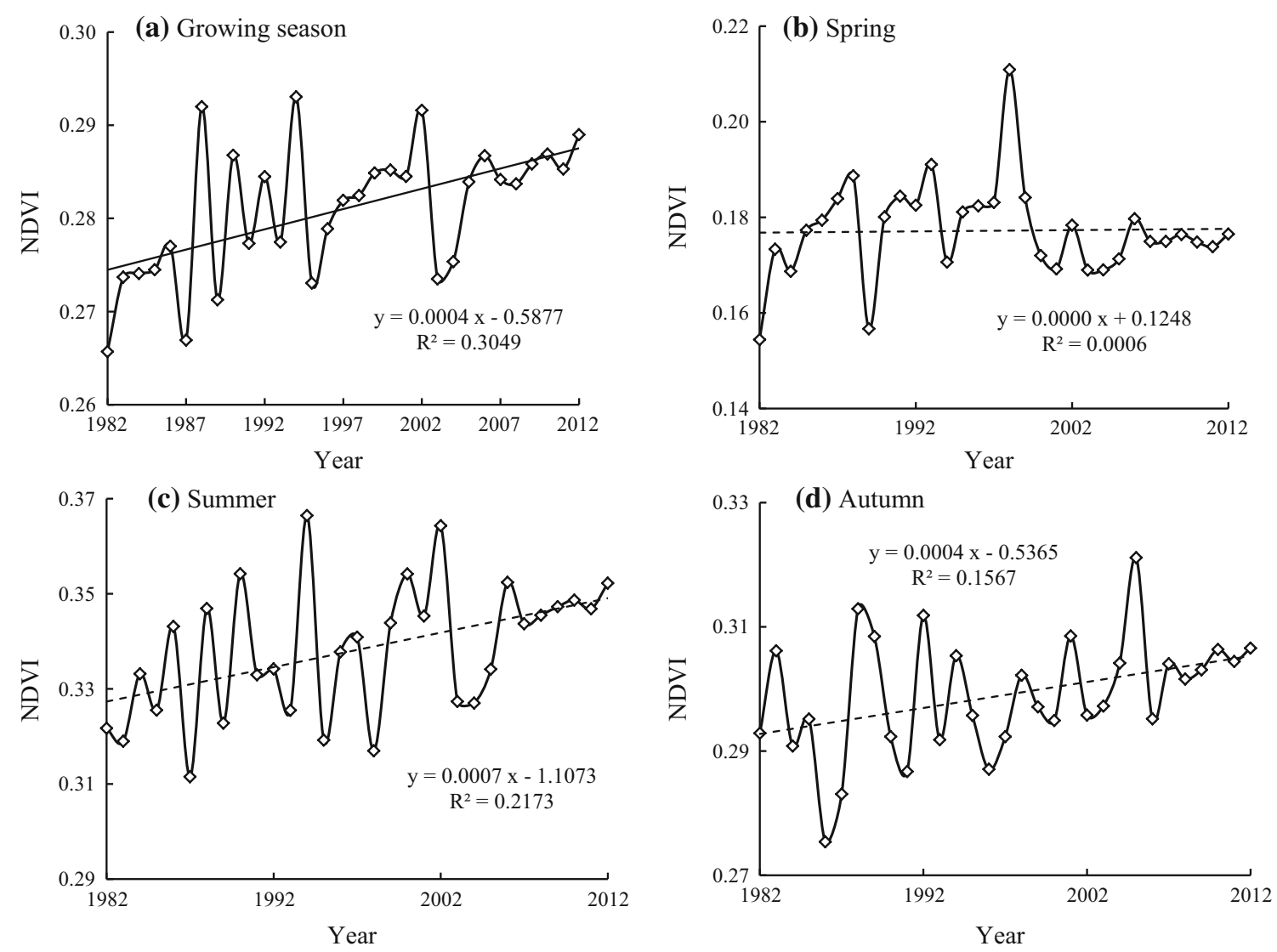

Fig. 4 Interannual variations of seasonal NDVI on the TP. Dashed lines indicate linear fit during the period of 1982-2012

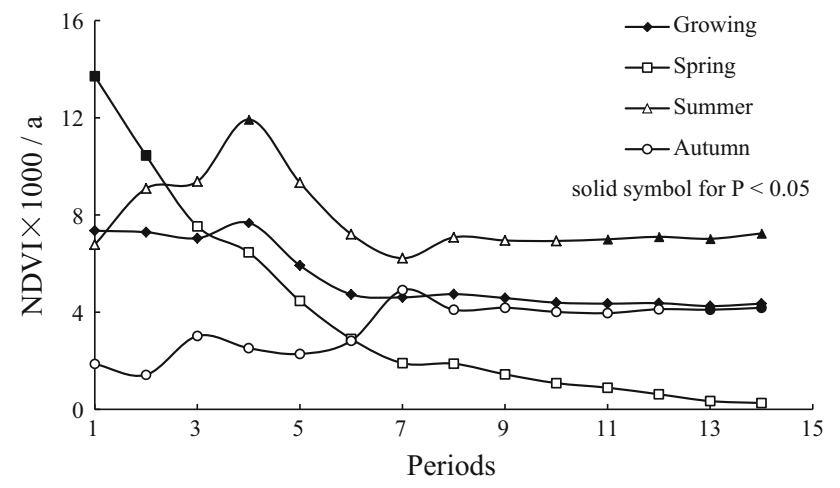

Fig. 5 Variations of seasonal NDVI interannual slope during 14 periods

precipitation increased high-significantly $\left(R^{2}=0.88\right.$, $R^{2}=0.89, R^{2}=0.70, n=14$ ) over the 14 periods while for spring there was no clear trend (Table 4). The pixels with significant negative correlation between spring NDVI and precipitation increased high-significantly $\left(R^{2}=0.97\right.$, $n=14$ ) over the 14 periods, while for growing season and the other seasons there was no clear trend. For growing season and summer, there was a significant positive correlation between NDVI and precipitation in the northeastern and southwestern TP, while a significant negative correlation occurred in parts of southeastern TP (Fig. 8). Less than $4 \%$ of the total study area, mainly in eastern locations of the TP, had a significant positive correlation between NDVI and precipitation for spring and autumn. The areas with significant negative correlation between spring NDVI and precipitation were mainly in the central and western TP, and for autumn mainly in the southeastern TP.

Similar to the patterns of correlation between NDVI and temperature, positive correlations between NDVI and sunshine duration for three seasons are common (Table 5). For growing season and spring, pixels with significant positive correlation between NDVI and sunshine duration increased significantly $\left(R^{2}=0.35, R^{2}=0.92, n=14\right)$ over the 14 periods while for summer and autumn there was no clear trend (Table 5). Pixels with significant negative correlation between NDVI and sunshine duration for growing season, summer, and autumn increased significantly $\left(R^{2}=0.82, R^{2}=0.94, R^{2}=0.41, n=14\right)$ over the 14 periods while for spring they decreased high-significantly $\left(R^{2}=0.97, n=14\right)$. For growing season and summer, NDVI significantly and positively correlated with sunshine duration in the eastern and southeastern TP, while 
Table 1 Percentage of the NDVI area displaying a statistically significant difference with progressively longer time series since 1982

\begin{tabular}{|c|c|c|c|c|c|c|c|c|c|c|c|c|}
\hline & \multicolumn{3}{|c|}{ Growing season } & \multicolumn{3}{|l|}{ Spring } & \multicolumn{3}{|c|}{ Summer } & \multicolumn{3}{|c|}{ Autumn } \\
\hline & $\mathrm{P}$ & $\mathrm{SN}$ & SP & $\mathrm{P}$ & SN & SP & $\mathrm{P}$ & $\mathrm{SN}$ & SP & $\mathrm{P}$ & $\mathrm{SN}$ & SP \\
\hline 1982-1999 & 76.17 & 0.88 & 16.29 & 88.15 & 0.11 & 23.02 & 67.75 & 1.38 & 10.95 & 56.56 & 1.60 & 3.38 \\
\hline 1982-2000 & 78.73 & 0.85 & 19.39 & 85.65 & 0.08 & 16.89 & 74.98 & 0.94 & 16.07 & 57.29 & 1.52 & 3.18 \\
\hline 1982-2001 & 78.28 & 0.97 & 23.03 & 79.14 & 0.27 & 13.89 & 75.19 & 0.93 & 19.01 & 62.46 & 1.01 & 4.43 \\
\hline 1982-2002 & 80.97 & 0.78 & 24.40 & 74.44 & 0.57 & 12.24 & 80.72 & 0.55 & 23.24 & 59.89 & 1.29 & 4.63 \\
\hline 1982-2003 & 77.14 & 1.50 & 22.15 & 66.73 & 1.58 & 10.36 & 76.86 & 1.03 & 20.81 & 59.85 & 1.72 & 5.58 \\
\hline 1982-2004 & 72.68 & 2.28 & 20.51 & 60.49 & 3.75 & 9.81 & 73.02 & 1.72 & 19.44 & 58.47 & 2.14 & 6.49 \\
\hline 1982-2005 & 70.00 & 2.82 & 21.75 & 54.95 & 7.27 & 9.08 & 70.25 & 2.44 & 18.64 & 64.14 & 2.05 & 10.15 \\
\hline 1982-2006 & 67.16 & 3.37 & 22.97 & 52.27 & 10.65 & 8.97 & 70.08 & 2.60 & 21.65 & 59.22 & 3.08 & 10.42 \\
\hline 1982-2007 & 66.89 & 4.10 & 24.69 & 50.55 & 12.89 & 9.55 & 70.03 & 3.11 & 23.46 & 59.57 & 3.70 & 12.13 \\
\hline 1982-2008 & 66.52 & 4.76 & 26.01 & 49.00 & 14.84 & 9.95 & 70.50 & 3.43 & 25.52 & 59.03 & 4.46 & 13.27 \\
\hline 1982-2009 & 66.61 & 5.32 & 27.29 & 48.12 & 16.59 & 10.95 & 70.72 & 3.85 & 27.31 & 58.79 & 5.23 & 14.72 \\
\hline 1982-2010 & 66.84 & 5.89 & 29.26 & 46.99 & 18.36 & 11.59 & 70.77 & 4.39 & 29.53 & 59.77 & 5.64 & 16.64 \\
\hline 1982-2011 & 66.95 & 6.40 & 30.47 & 45.86 & 20.09 & 11.94 & 71.11 & 4.58 & 31.18 & 60.00 & 6.05 & 18.04 \\
\hline 1982-2012 & 66.99 & 7.02 & 31.47 & 45.25 & 21.15 & 12.36 & 70.79 & 5.10 & 32.86 & 60.56 & 6.71 & 19.22 \\
\hline
\end{tabular}

$\mathrm{N}, \mathrm{P}$, and $\mathrm{S}$ represent $R<0, R>0$, and the statistical significance of the linear regression of the Pearson correlation less than 0.05 , respectively the correlation was significant but negative at locations within southwestern and northeastern TP (Fig. 8). Areas with significantly positive correlation between NDVI and sunshine duration for spring and autumn were scattered over the entire TP.

In general, spatial patterns of correlation between NDVI and either temperature, precipitation or sunshine duration were mostly similar among the 14 periods but, in some TP locations, the positive or negative correlations between NDVI and climatic variables reversed.

\section{Discussion}

\section{Integrated use of GIMMS and MODIS NDVI datasets}

Differences between AVHRR and MODIS sensors involve bandwidths and spectral response functions. Hence, the combined use of the two data sets requires initial testing for continuity and consistency (Brown et al. 2006; Mao et al. 2012; Steven et al. 2003). Data comparison is an effective method for evaluating the continuity of data collected from different sensors (Fontana et al. 2012; Steven et al. 2003). A previous study (Du et al. 2014) on independently assessing the performance of GIMMS and MODIS NDVI using Landsat samples indicated that spatial patterns and dynamic trends of GIMMS NDVI were in overall acceptable agreement with MODIS NDVI. Correlations and differences between the two datasets on the TP are both superior to those from corresponding results in other arid regions of the world (Fensholt et al. 2012), and in northeast
China (Mao et al. 2012). This indicates that the GIMMS and MODIS NDVI datasets show relatively high agreement on the TP and that the use of the MODIS to extend the time series of the GIMMS is appropriate. The continuity and consistency of the spatial pattern of NDVI trends in the 14 periods in the majority of the TP also indirectly verified the accuracy of the simulated GIMMS NDVI data using the MODIS data.

\section{Changes in NDVI and its association with climate change}

An overall increasing trend in NDVI on the TP during the first few periods in this study was in agreement with previous studies (Ding et al. 2010; Mao et al. 2007; Peng et al. 2012b; Yang et al. 2005, 2006; Zhang et al. 2010). The spatial patterns of vegetation growth were also similar to most of the previous studies (Peng et al. 2011, 2012b; Piao et al. 2011; Yang and Piao 2006; Zhang et al. 2010) but there were discrepancies with the results of Ding et al. (2010). Possible reasons for this include: (1) data used to extend the GIMMS NDVI time sequence were differentDing et al. (2010) used the SPOT VGT dataset; and (2) integration methods differed - the present study adopted per-pixel regression during 2000-2006 at month scale while Ding et al. (2010) used all pixels in 1999 as a variable in the regression model.

The reduction of the increasing rate of the growing season NDVI over 14 periods were contributed by spring and summer NDVI changes, and in particular, by spring NDVI change. Although the slowing of growing season, spring, and summer NDVI change was observed on a 

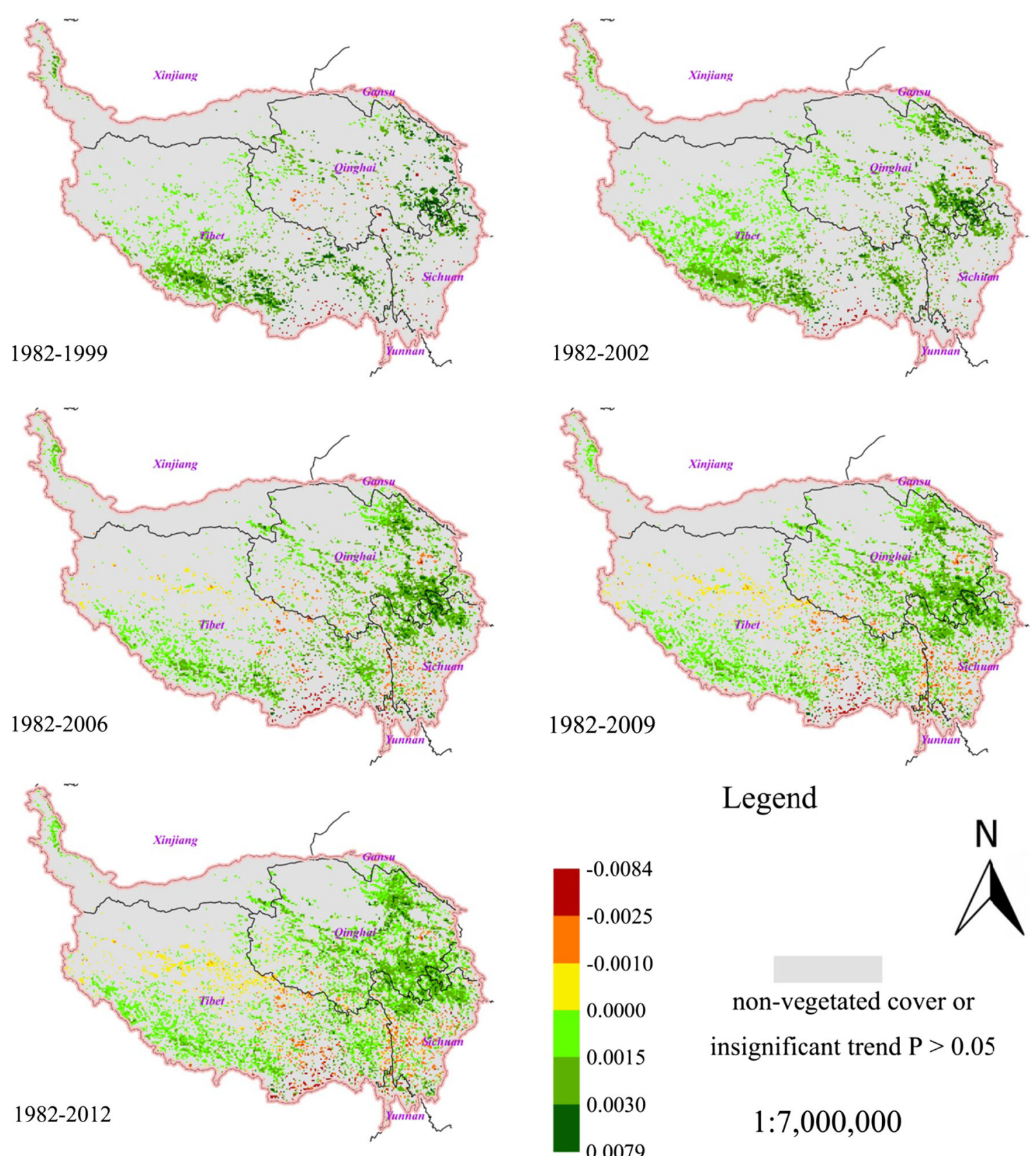

\section{Legend}

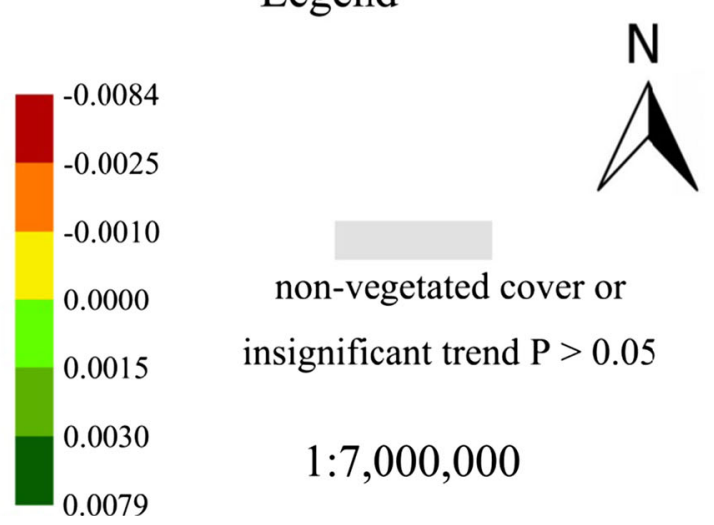

Fig. 6 Spatial distribution of trends in growing season NDVI during 1982-1999, 1982-2002, 1982-2006, 1982-2009, and 1982-2012

regional scale over 14 periods, area with both positive and negative significant NDVI trends was significantly increased in most seasons. This was especially evident in areas with significant negative trends leading to a significant decrease in the rate of NDVI change at the regional scale. Thus, the regional average may mask or obscure phenomenon existing at the pixel scale and may miss some important ecological processes arisen at the pixel scale.

The NDVI-temperature correlation was generally stronger than the NDVI-precipitation and the NDVI-sunshine duration correlation in the growing season and all individual seasons. The area with significant NDVI-temperature correlation was also larger than the areas with significant NDVI-precipitation and NDVI-sunshine duration. Related studies (Mao et al. 2007; Xu et al. 2011; Yang and Piao 2006; Zhang et al. 2010) also indicate that vegetation growth on the TP is more strongly related to temperature than to other climatic variables. Increased temperature enhanced vegetation growth in the eastern TP, particularly in the Qinghai Province. Increased precipitation also enhanced NDVI in northeastern Qinghai and southwestern Tibetan. Over a gradually increasing time 

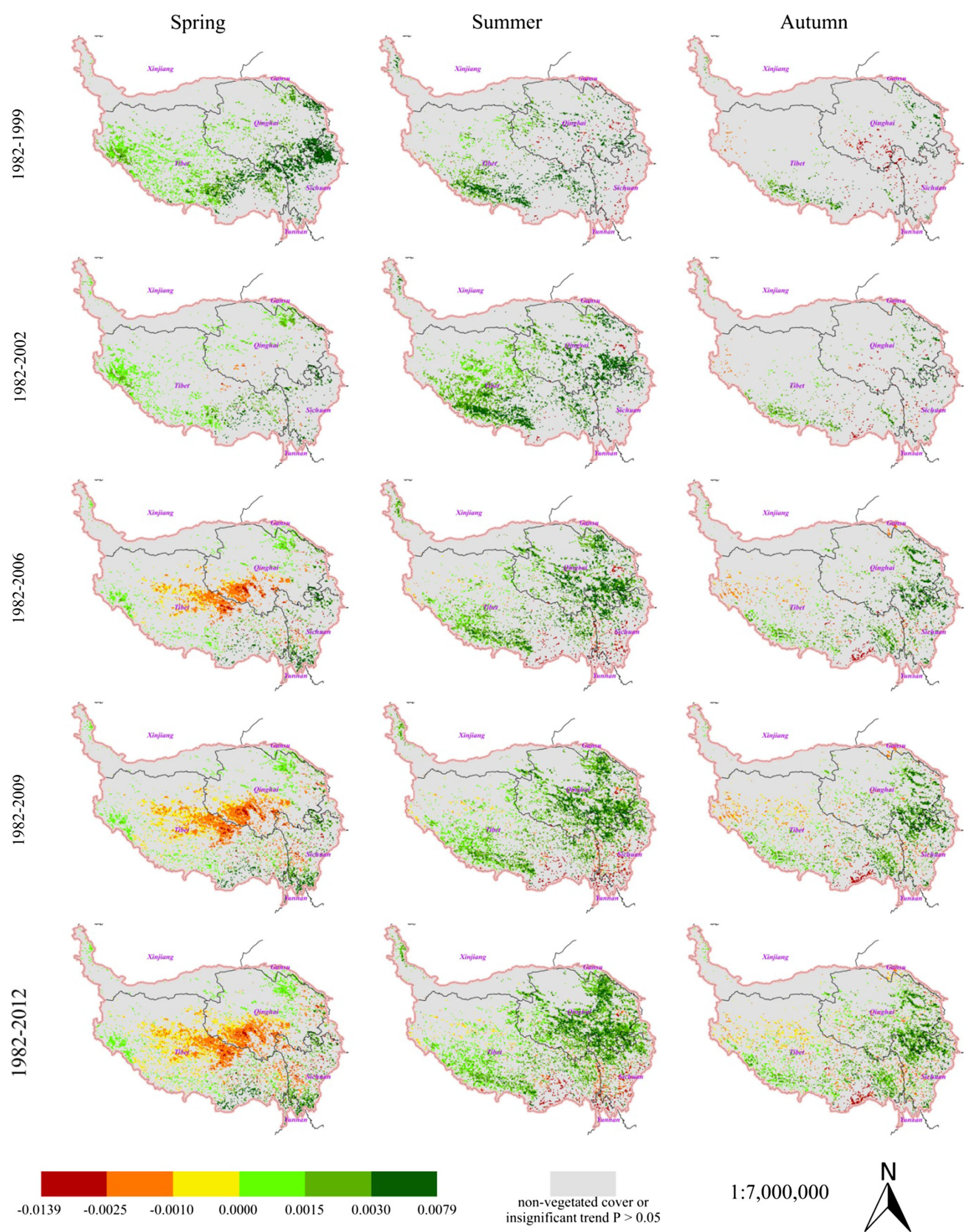

1:7,000,000

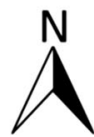

Fig. 7 Spatial distribution of seasonal NDVI trends over Xinjiang during the 1982-1999, 1982-2002, 1982-2006, 1982-2009, and 1982-2012 


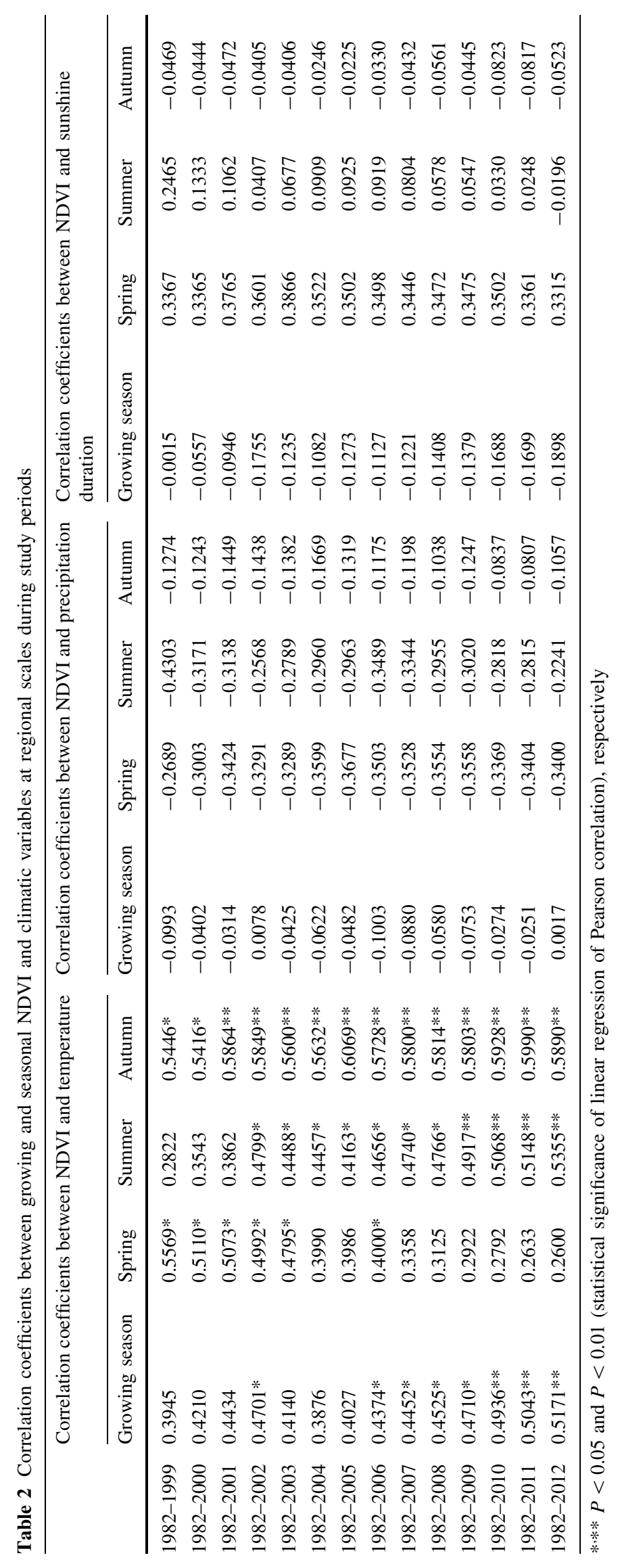


Table 3 Area percentages displaying statistical significance levels of the correlation between NDVI and temperature with progressively longer time series since 1982

\begin{tabular}{|c|c|c|c|c|c|c|c|c|c|c|c|c|}
\hline & \multicolumn{3}{|c|}{ Growing season } & \multicolumn{3}{|c|}{ Spring } & \multicolumn{3}{|c|}{ Summer } & \multicolumn{3}{|c|}{ Autumn } \\
\hline & $\mathrm{P}$ & $\mathrm{SN}$ & SP & $\mathrm{P}$ & $\mathrm{SN}$ & SP & $\mathrm{P}$ & $\mathrm{SN}$ & SP & $\mathrm{P}$ & $\mathrm{SN}$ & SP \\
\hline 1982-1999 & 66.85 & 0.83 & 5.98 & 86.55 & 0.18 & 28.38 & 51.88 & 3.45 & 3.89 & 76.75 & 0.17 & 10.33 \\
\hline 1982-2000 & 69.12 & 0.84 & 6.87 & 86.22 & 0.17 & 28.90 & 57.34 & 3.18 & 5.85 & 77.08 & 0.21 & 10.55 \\
\hline 1982-2001 & 69.90 & 1.05 & 8.30 & 86.97 & 0.17 & 31.41 & 58.84 & 3.23 & 6.30 & 78.52 & 0.20 & 14.02 \\
\hline 1982-2002 & 70.95 & 1.06 & 9.44 & 86.67 & 0.18 & 30.71 & 62.83 & 2.91 & 9.46 & 79.00 & 0.18 & 13.77 \\
\hline 1982-2003 & 68.01 & 1.54 & 9.27 & 86.26 & 0.22 & 29.48 & 61.69 & 3.01 & 9.29 & 77.70 & 0.24 & 14.95 \\
\hline 1982-2004 & 66.63 & 1.68 & 9.50 & 82.33 & 0.32 & 26.99 & 62.69 & 2.78 & 9.67 & 76.80 & 0.27 & 14.78 \\
\hline 1982-2005 & 66.42 & 1.85 & 11.25 & 83.26 & 0.28 & 27.35 & 59.45 & 3.19 & 10.42 & 78.53 & 0.25 & 17.67 \\
\hline 1982-2006 & 64.94 & 2.04 & 13.66 & 82.23 & 0.27 & 27.01 & 61.04 & 2.70 & 14.85 & 78.70 & 0.31 & 17.34 \\
\hline 1982-2007 & 64.37 & 2.24 & 15.14 & 78.92 & 0.30 & 24.26 & 61.63 & 2.81 & 16.11 & 77.92 & 0.39 & 17.85 \\
\hline 1982-2008 & 64.32 & 2.42 & 16.19 & 76.77 & 0.44 & 22.95 & 61.38 & 2.93 & 16.12 & 78.18 & 0.37 & 18.49 \\
\hline 1982-2009 & 64.59 & 2.68 & 17.97 & 74.49 & 0.58 & 21.92 & 62.33 & 2.49 & 17.72 & 77.47 & 0.46 & 19.31 \\
\hline 1982-2010 & 64.75 & 3.14 & 20.34 & 72.42 & 0.89 & 21.47 & 63.22 & 2.63 & 20.13 & 77.55 & 0.55 & 20.96 \\
\hline 1982-2011 & 64.82 & 3.48 & 21.63 & 71.64 & 1.11 & 21.77 & 63.24 & 2.81 & 20.83 & 77.50 & 0.64 & 22.15 \\
\hline 1982-2012 & 65.05 & 3.67 & 21.84 & 70.85 & 1.19 & 21.38 & 63.92 & 3.11 & 21.94 & 77.41 & 0.63 & 21.05 \\
\hline
\end{tabular}

for growing season, summer, and autumn. This indicates that the effect of increasing temperature on vegetation greening is still effective. The influence of increasing temperature on vegetation growth may differ among seasons. In spring, temperature increased significantly $\left(R^{2} \geq 0.38, n=18-31\right)$ during all 14 periods, but NDVI decreased after 1998. A possible explanation is that vegetation increase driven by warming may be counterbalanced by inhibition of vegetation growth brought by wet trend and reduction of sunshine duration, and this resulted in a net NDVI declining during the last decade.

Temperature is a major limiting factor for vegetation growth and the responses of vegetation growth to climate change are likely to vary across different seasons and regions. The areas with a significant negative correlation between NDVI and precipitation are larger than areas with significant positive correlation for spring and autumn. The opposite is true for correlations between NDVI and temperature and sunshine duration. This suggests that vegetation growth in spring and autumn on large parts of the TP is mainly controlled by temperature and sunshine duration, which are both components of thermal conditions. Significant positive correlation between NDVI and precipitation and significant negative correlation between NDVI and sunshine duration generally dominates in both the southwestern and northeastern $\mathrm{TP}$, where precipitation and sunshine is relatively less and abundant, respectively. But on the southeastern TP with more precipitation and less sunshine, correlations between NDVI and precipitation were negative, and correlations between NDVI and sunshine duration were positive. Ecological restoration projects during the last decade have promoted the vegetation cover in Three-River Source 

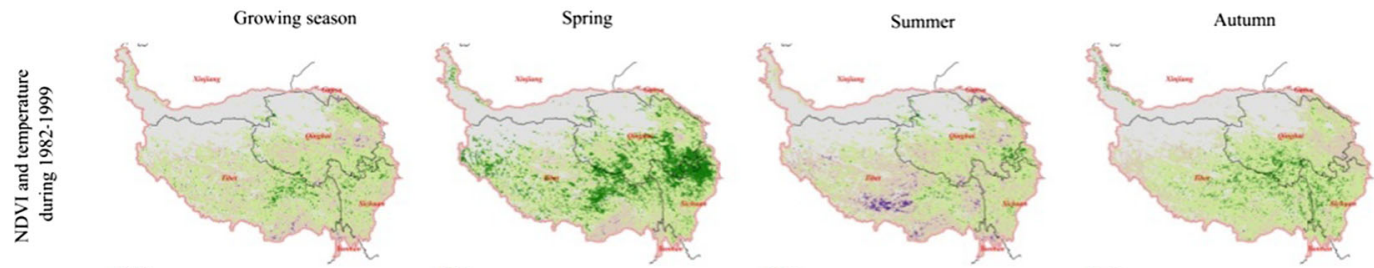

$\Lambda$
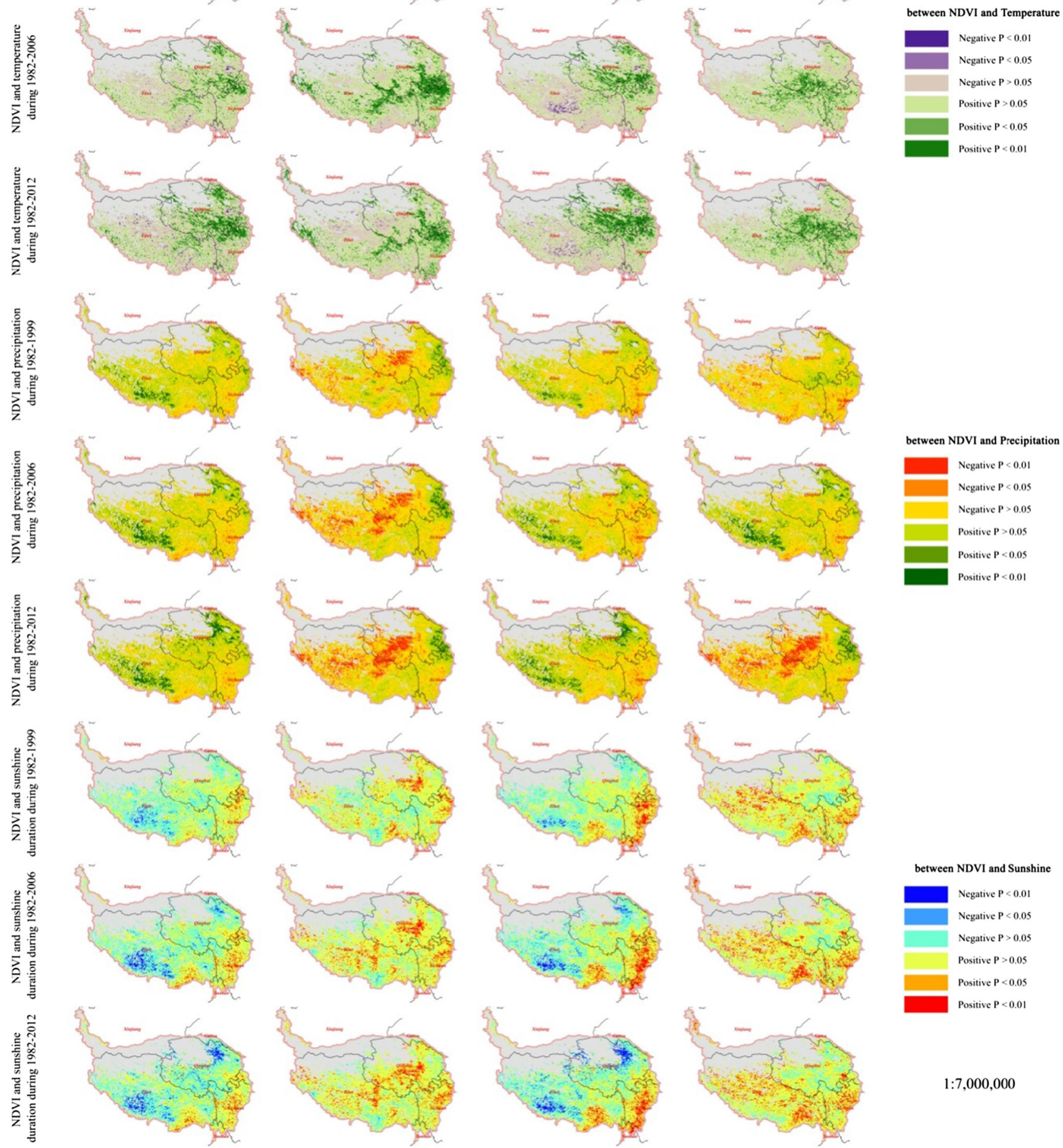

between NDVI and Temperature

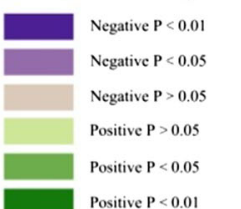

Fig. 8 Spatial distributions of correlations between NDVI and climatic factors (temperature, precipitation and sunshine duration) in the growing season and individual seasons during 1982-1999 and 1982-2012 
Table 4 Area percentages with statistical significance of the correlation between NDVI and precipitation related to progressively longer time series beginning in 1982
Table 5 Area percentages with statistical significance of the correlation between NDVI and sunshine duration with progressively longer time series since 1982

\begin{tabular}{|c|c|c|c|c|c|c|c|c|c|c|c|c|}
\hline & \multicolumn{3}{|c|}{ Growing season } & \multicolumn{3}{|l|}{ Spring } & \multicolumn{3}{|c|}{ Summer } & \multicolumn{3}{|c|}{ Autumn } \\
\hline & $\mathrm{P}$ & SN & SP & $\mathrm{P}$ & SN & SP & $\mathrm{P}$ & SN & SP & $\mathrm{P}$ & $\mathrm{SN}$ & SP \\
\hline 1982-1999 & 58.26 & 1.78 & 6.23 & 34.12 & 10.21 & 2.69 & 43.29 & 4.08 & 3.18 & 28.03 & 8.23 & 0.90 \\
\hline 1982-2000 & 61.34 & 1.85 & 8.43 & 33.16 & 9.81 & 3.23 & 46.59 & 4.22 & 5.06 & 27.49 & 8.68 & 0.90 \\
\hline 1982-2001 & 61.28 & 1.99 & 8.68 & 30.90 & 11.67 & 3.33 & 47.09 & 4.67 & 5.51 & 27.08 & 9.89 & 0.79 \\
\hline 1982-2002 & 58.71 & 2.48 & 8.71 & 30.95 & 12.09 & 3.33 & 46.17 & 5.97 & 5.62 & 26.67 & 10.85 & 0.75 \\
\hline 1982-2003 & 55.92 & 2.86 & 8.70 & 30.87 & 12.00 & 3.33 & 44.40 & 7.23 & 5.44 & 26.86 & 11.15 & 0.67 \\
\hline 1982-2004 & 54.82 & 3.13 & 8.79 & 29.50 & 13.70 & 3.42 & 43.84 & 7.29 & 5.69 & 27.89 & 8.46 & 0.74 \\
\hline 1982-2005 & 57.28 & 2.52 & 9.38 & 28.36 & 13.57 & 3.52 & 45.68 & 5.89 & 6.34 & 29.67 & 8.90 & 0.85 \\
\hline 1982-2006 & 56.45 & 2.68 & 8.95 & 27.31 & 15.76 & 3.18 & 44.36 & 5.59 & 5.79 & 30.68 & 7.70 & 0.90 \\
\hline 1982-2007 & 56.79 & 2.73 & 9.63 & 27.29 & 15.74 & 3.34 & 45.07 & 5.54 & 6.36 & 30.61 & 7.98 & 1.02 \\
\hline 1982-2008 & 56.72 & 2.89 & 10.18 & 27.22 & 17.50 & 3.33 & 46.09 & 5.89 & 7.21 & 31.47 & 8.34 & 1.14 \\
\hline 1982-2009 & 58.56 & 2.42 & 10.47 & 27.28 & 18.86 & 3.26 & 48.15 & 5.30 & 7.47 & 32.12 & 8.11 & 1.34 \\
\hline 1982-2010 & 58.98 & 2.61 & 11.31 & 27.88 & 19.04 & 3.21 & 48.65 & 5.20 & 8.18 & 32.42 & 8.30 & 1.41 \\
\hline 1982-2011 & 59.08 & 2.51 & 11.92 & 27.46 & 20.87 & 3.22 & 48.89 & 5.34 & 8.73 & 33.47 & 8.35 & 1.50 \\
\hline 1982-2012 & 60.05 & 2.38 & 12.08 & 27.62 & 20.03 & 3.06 & 50.82 & 4.74 & 9.72 & 33.24 & 8.09 & 1.35 \\
\hline
\end{tabular}

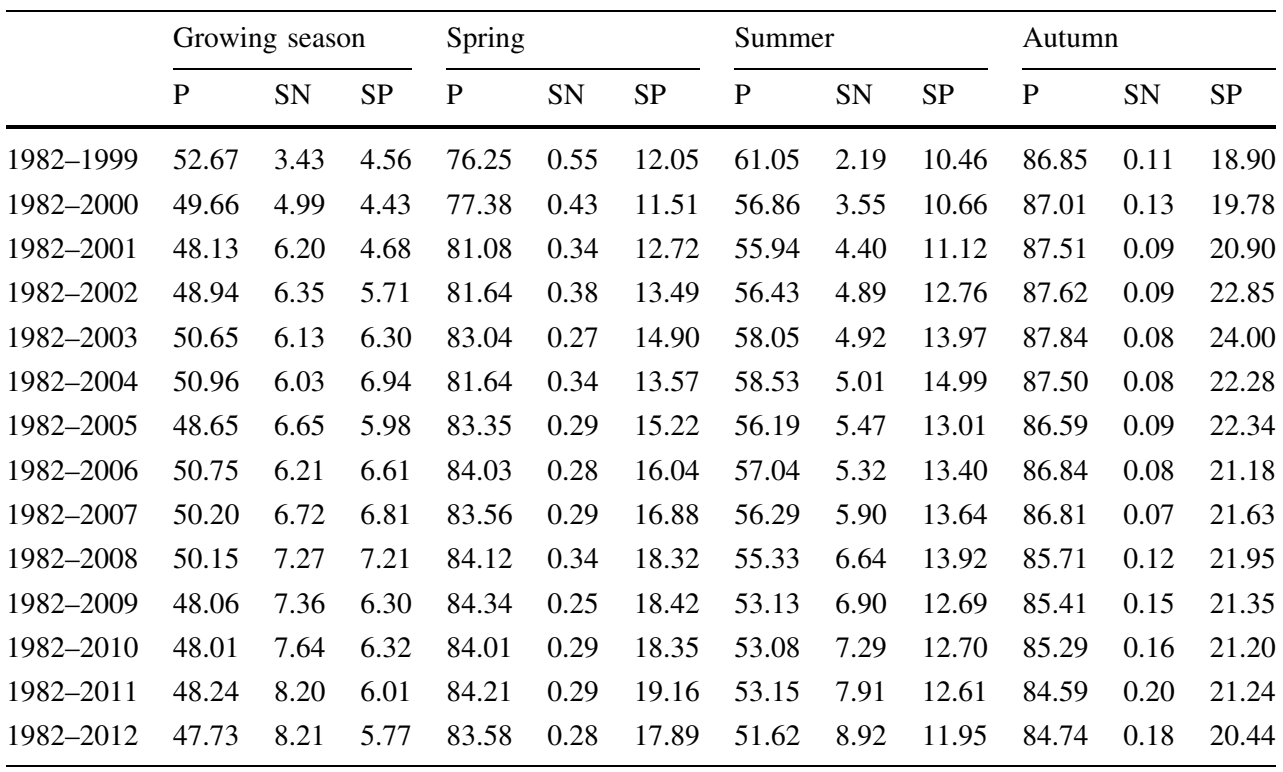

Regions, which is located in central part of the TP (Xu et al. 2011).

Linear regression is simple, robust, and the results are easy to interpret (Fensholt et al. 2009; Peng et al. 2012b) but the overall linear trend is a simplification of the actual temporal patterns of vegetation growth change during the entire study period (de Jong et al. 2011, 2012; Piao et al. 2011). For example, spring NDVI on the TP exhibits combined greening and browning trends, which are averaged out by a simple linear trend analysis during whole period. It is difficult to simulate expected future vegetation changes using general ecological models (Xu et al. 2014; Yu et al. 2012) due to the time lag effects of vegetation growth to climate change (Yang and Piao 2006; Yu et al. 2012). Detection of spatio-temporal changes of NDVI and its relationship with climatic factors during multiple nested periods may become one of the methods that can provide a solution to problems involved with studies of current and projected vegetation change. Over progressively longer periods since the beginning year of the study (1982), monitoring the changes of vegetation growth and analyzing the trend in the annual variation rates of NDVI during each period provided an alternative way of forecasting vegetation change. Based on results of this paper, it can thus be predict that spring NDVI will continue to decrease, autumn NDVI will continue to increase, and the magnitude of 


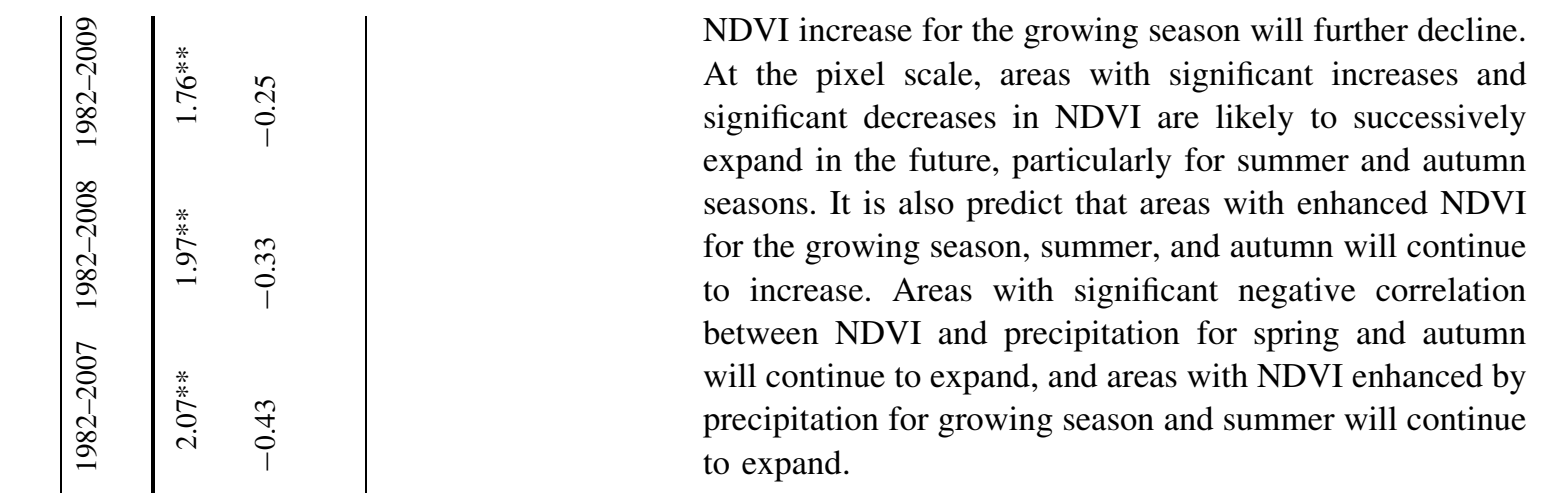

\section{Conclusions}

The GIMMS and the MODIS NDVI datasets are consistent and can be merged to expand the length of the NDVI time series on the TP. From 1982 to 2012, vegetation growth on the TP showed an overall increasing tendency for growing season and three seasons. Comparison of NDVI changes among multiple periods indicated that although the rate of NDVI increase in autumn significantly increased as the time period lengthened, but in spring and summer significantly decreased and slightly decreased, respectively. This led to the increase in growing season NDVI was stagnant or slowdown over 14 periods, which means vegetation activity tends to be stable.

The NDVI trends had remarkable regional differences and showed divergence. Areas with significant change mostly increased in size as the NDVI record length increased from 1982-1999 to 1982-2012. Regional averages can mask or obscure significant trends occurring at the pixel scale.

The main climatic drivers of vegetation growth varied across seasons and regions. Vegetation growth in spring and autumn was mainly regulated by thermal factors, such as temperature and sunshine duration. NDVI decrease in spring may have been caused by increased precipitation and reduction of sunshine duration during the last decade of study records. The relatively wet and reduced sunshine conditions in the southeastern TP produced a significant negative correlation between NDVI and precipitation and a significant positive correlation between NDVI and sunshine duration.

In research focusing on long time sequences of NDVI, trend analysis during the multiple progressive time series may contribute to a better understanding of NDVI changes and provide insight regarding future changes. In this respect, spring NDVI will be expected to continue to decrease, autumn NDVI will continuously increase but the magnitude of NDVI increase for the growing season will be reduced in the future. Areas with significant NDVI trends (both positive and negative) for the growing season 


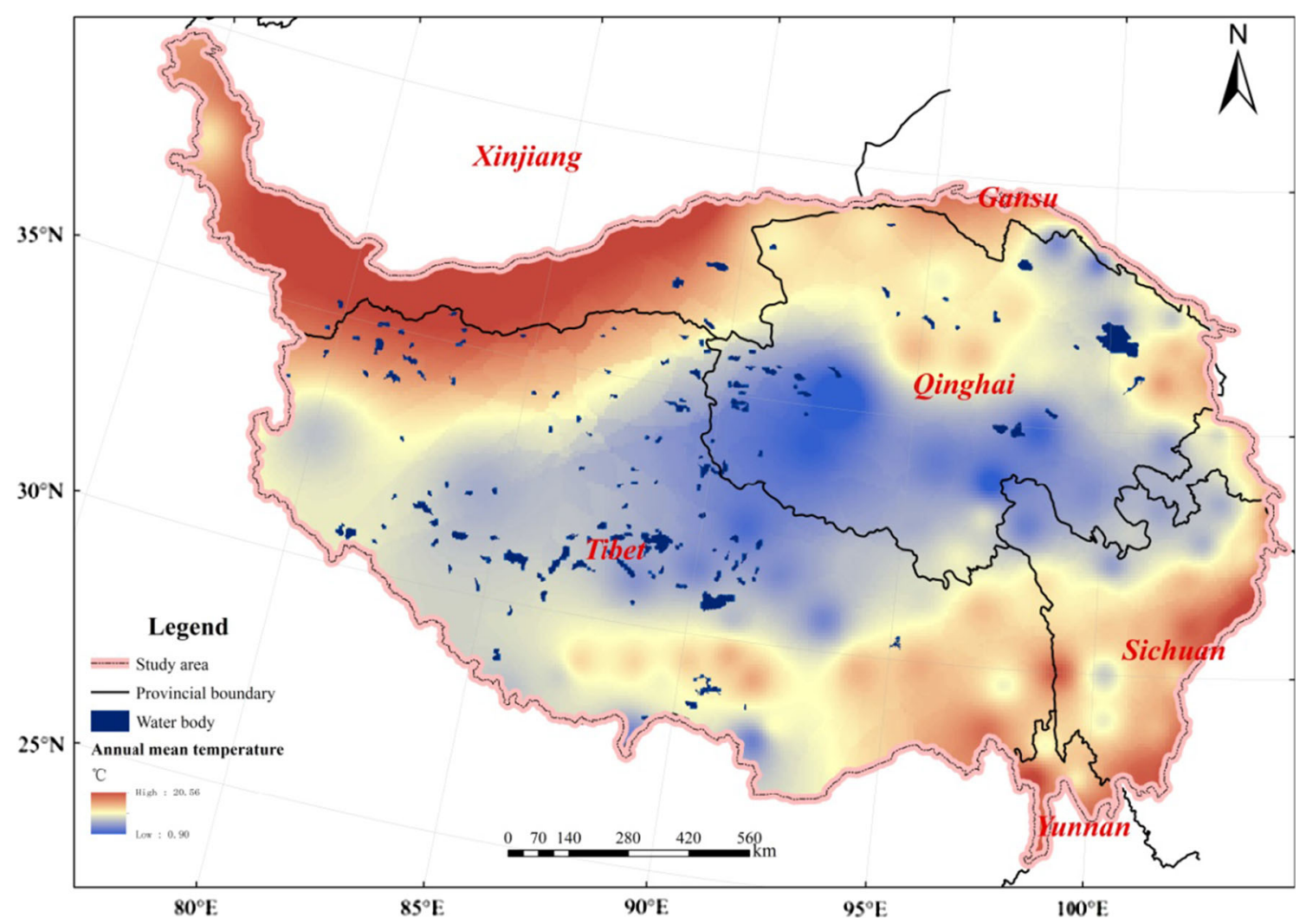

Fig. 9 Annual mean temperatures on the TP

and the three individual seasons are likely to maintain increasing trends.

Acknowledgments This study was supported by the National Natural Science Foundation of China (Grant 41001055), the Special Fund of Environment Protection Research in the Public Interest (Grant 201209027-5) and the Fundamental Research Funds for the Central Public-interest Scientific Institution (Grant 2009KYYW10 and 2012-YSKY-13). The authors thank the NASA Global Inventory Modeling and Mapping Studies (GIMMS) group for producing and sharing the AVHRR GIMMS NDVI datasets. NASA/MODIS Land Discipline Group is thanked for sharing the MODIS LAND data.

\section{References}

Beck PSA, Goetz SJ (2011) Satellite observations of high northern latitude vegetation productivity changes between 1982 and 2008: ecological variability and regional differences. Environ Res Lett 6:5501-5511

Beck HE, McVicar TR, van Dijk AIJM, Schellekens J, de Jeu RAM, Bruijnzeel LA (2011) Global evaluation of four AVHRR-NDVI data sets: intercomparison and assessment against Landsat imagery. Remote Sens Environ 115:2547-2563. doi:10.1016/j. rse.2011.05.012

Brown ME, Pinzon JE, Didan K, Morisette JT, Tucker CJ (2006) Evaluation of the consistency of long-term NDVI time series derived from AVHRR, SPOT-vegetation, SeaWiFS, MODIS, and Landsat ETM + sensors. IEEE Trans Geosci Remote Sens 44:1787-1793. doi:10.1109/TGRS.2005.860205
Chen Y, Long B, Pan X, Zhong S, Mo H (2011) Differences between MODIS NDVI and AVHRR NDVI in monitoring grasslands change. J Remote Sens 15:831-845

China ECfVMo (2001) Vegetation Atlas of China. Science Press, Beijing

Cuo L, Zhang Y, Wang Q, Zhang L, Zhou B, Hao Z, Su F (2012) Climate change on the Northern Tibetan Plateau during 1957-2009: spatial patterns and possible mechanisms. J Clim 26:85-109. doi:10.1175/JCLI-D-11-00738.1

de Jong R, de Bruin S, Schaepman M, Dent D (2011) Quantitative mapping of global land degradation using Earth observations. Int J Remote Sens 32:6823-6853. doi:10.1080/01431161.2010. 512946

de Jong R, Verbesselt J, Schaepman ME, de Bruin S (2012) Trend changes in global greening and browning: contribution of shortterm trends to longer-term change. Glob Change Biol 18:642-655. doi:10.1111/j.1365-2486.2011.02578.x

Ding M, Zhang Y, Liu L, Wang Z (2010) Temporal and spatial distribution of grassland coverage change in Tibetan Plateau since 1982. J Nat Resour 25:2114-2122

Du J, Shu J, Wang Y, Li Y, Zhang L, Guo Y (2014) Comparison of GIMMS and MODIS normalized vegetation index composite data for Qinghai-Tibet Plateau. Chin J Appl Ecol 25:533-544

Duan A, Li F, Wang M, Wu G (2011) Persistent weakening trend in the spring sensible heat source over the Tibetan Plateau and its impact on the Asian summer monsoon. J Clim 24:5671-5682. doi:10.1175/JCLI-D-11-00052.1

Duan A, Wang M, Lei Y, Cui Y (2012a) Trends in summer rainfall over China associated with the Tibetan Plateau sensible heat source during 1980-2008. J Clim 26:261-275. doi:10.1175/ JCLI-D-11-00669.1 
Duan A, Wu G, Liu Y, Ma Y, Zhao P (2012b) Weather and climate effects of the Tibetan Plateau. Adv Atmos Sci 29:978-992. doi:10.1007/s00376-012-1220-y

Fensholt R, Rasmussen K, Nielsen TT, Mbow C (2009) Evaluation of earth observation based long term vegetation trends-intercomparing NDVI time series trend analysis consistency of Sahel from AVHRR GIMMS. Terra MODIS SPOT VGT Data Remote Sens Environ 113:1886-1898. doi:10.1016/j.rse.2009.04.004

Fensholt R, Langanke T, Rasmussen K, Reenberg A, Prince SD, Tucker C, Scholes RJ, Le QB et al (2012) Greenness in semi-arid areas across the globe 1981-2007-an earth observing satellite based analysis of trends and drivers. Remote Sens Environ 121:144-158. doi:10.1016/j.rse.2012.01.017

Fontana FMA, Coops NC, Khlopenkov KV, Trishchenko AP, Riffler M, Wulder MA (2012) Generation of a novel $1 \mathrm{~km}$ NDVI data set over Canada, the northern United States, and Greenland based on historical AVHRR data. Remote Sens Environ 121:171-185. doi:10.1016/j.rse.2012.01.007

Gallo K, Ji L, Reed B, Eidenshink J, Dwyer J (2005) Multi-platform comparisons of MODIS and AVHRR normalized difference vegetation index data. Remote Sens Environ 99:221-231. doi:10. 1016/j.rse.2005.08.014

Goetz SJ, Bunn AG, Fiske GJ, Houghton RA (2005) Satelliteobserved photosynthetic trends across boreal North America associated with climate and fire disturbance. Proc Natl Acad Sci 102:13521-13525

He Y, Fan G, Zhang X, Liu M, Gao D (2012) Variation of vegetation NDVI and its response to climate change in Zhejiang Province. Acta Ecol Sin 32:4352-4362

Huang L, Liu J, Shao Q, Liu R (2011) Changing inland lakes responding to climate warming in Northeastern Tibetan Plateau. Clim Change 109:479-502. doi:10.1007/s10584-011-0032-x

Huete A, Didan K, Miura T, Rodriguez EP, Gao X, Ferreira LG (2002) Overview of the radiometric and biophysical performance of the MODIS vegetation indices. Remote Sens Environ 83:195-213. doi:10.1016/S0034-4257(02)00096-2

Jeong S-J, Ho C-H, Gim H-J, Brown ME (2011) Phenology shifts at start vs. end of growing season in temperate vegetation over the Northern Hemisphere for the period 1982-2008. Glob Change Biol 17:2385-2399. doi:10.1111/j.1365-2486.2011.02397.x

Liu X, Wang Y (2011) Contrasting impacts of spring thermal conditions over Tibetan Plateau on late-spring to early-summer precipitation in southeast China. Atmos Sci Lett 12:309-315. doi:10.1002/asl.343

Mao F, Lu Z, Zhang J, Hou Y (2007) Relations between AVHRR NDVI and climate factors in northern Tibet in recent 20 years. Acta Ecol Sin 27:3198-3205

Mao D, Wang Z, Luo L, Ren C (2012) Integrating AVHRR and MODIS data to monitor NDVI changes and their relationships with climatic parameters in Northeast China. Int J Appl Earth Obs Geoinf 18:528-536. doi:10.1016/j.jag.2011.10.007

Mohammat A, Wang X, Xu X, Peng L, Yang Y, Zhang X, Myneni RB, Piao S (2013) Drought and spring cooling induced recent decrease in vegetation growth in Inner Asia. Agric Forest Meteorol 178-179:21-30. doi:10.1016/j.agrformet.2012.09.014

Myneni RB, Keeling CD, Tucker CJ, Asrar G, Nemani RR (1997) Increased plant growth in the northern high latitudes from 1981 to 1991. Nature 386:698-702. doi:10.1038/386698a0

Peng S, Chen A, Xu L, Cao C, Fang J, Myneni RB, Pinzon JE, Tucker CJ et al (2011) Recent change of vegetation growth trend in China. Environ Res Lett 6:4027-4029

Peng J, Dong W, Yuan W, Zhang Y (2012a) Responses of grassland and forest to temperature and precipitation changes in Northeast China. Adv Atmos Sci 29:1063-1077. doi:10.1007/s00376-012$1172-2$
Peng J, Liu Z, Liu Y, Wu J, Han Y (2012b) Trend analysis of vegetation dynamics in Qinghai-Tibet Plateau using Hurst Exponent. Ecol Ind 14:28-39. doi:10.1016/j.ecolind.2011.08.011

Piao S, Cui M, Chen A, Wang X, Ciais P, Liu J, Tang Y (2011a) Altitude and temperature dependence of change in the spring vegetation green-up date from 1982 to 2006 in the QinghaiXizang Plateau. Agric Forest Meteorol 151:1599-1608. doi:10. 1016/j.agrformet.2011.06.016

Piao S, Wang X, Ciais P, Zhu B, Wang TAO, Liu JIE (2011b) Changes in satellite-derived vegetation growth trend in temperate and boreal Eurasia from 1982 to 2006 . Glob Change Biol 17:3228-3239. doi:10.1111/j.1365-2486.2011.02419.x

Qin J, Yang K, Liang S, Guo X (2009) The altitudinal dependence of recent rapid warming over the Tibetan Plateau. Clim Change 97:321-327. doi:10.1007/s10584-009-9733-9

Shen M, Zhang G, Cong N, Wang S, Kong W, Piao S (2014) Increasing altitudinal gradient of spring vegetation phenology during the last decade on the Qinghai-Tibetan Plateau. Agric Forest Meteorol 189-190:71-80. doi:10.1016/j.agrformet.2014.01.003

Shichang K, Yanwei X, Qinglong Y, Wolfgang-Albert F, Nick P, Tandong Y (2010) Review of climate and cryospheric change in the Tibetan Plateau. Environ Res Lett 5:015101

Steven MD, Malthus TJ, Baret F, Xu H, Chopping MJ (2003) Intercalibration of vegetation indices from different sensor systems. Remote Sens Environ 88:412-422. doi:10.1016/j.rse. 2003.08.010

Sun H, Zheng D, Yao T, Zhang Y (2012) Protection and construction of the national ecological security shelter zone on Tibetan Plateau. Acta Geogr Sin 67:3-12

Tucker C, Pinzon J, Brown M, Slayback D, Pak E, Mahoney R, Vernote E, Saleous NE (2005) An extended AVHRR 8-km NDVI dataset compatible with MODIS and SPOT vegetation NDVI data. Int J Remote Sens 26:4485-4498. doi:10.1080/ 01431160500168686

van Leeuwen WJD, Orr BJ, Marsh SE, Herrmann SM (2006) Multisensor NDVI data continuity: uncertainties and implications for vegetation monitoring applications. Remote Sens Environ 100:67-81. doi:10.1016/j.rse.2005.10.002

Xu W, Gu S, Zhao X, Xiao J, Tang Y, Fang J, Zhang J, Jiang S (2011) High positive correlation between soil temperature and NDVI from 1982 to 2006 in alpine meadow of the Three-River Source Region on the Qinghai-Tibetan Plateau. Int J Appl Earth Obs Geoinf 13:528-535. doi:10.1016/j.jag.2011.02.001

Xu X, Piao S, Wang X, Chen A, Ciais P, Myneni RB (2012) Spatiotemporal patterns of the area experiencing negative vegetation growth anomalies in China over the last three decades. Environ Res Lett 7:35701

Xu G, Zhang H, Chen B, Zhang H, Innes J, Wang G, Yan J, Zheng Y et al (2014) Changes in vegetation growth dynamics and relations with climate over China's landmass from 1982 to 2011. Remote Sens 6:3263-3283

Yang Y, Piao S (2006) Variations in grassland vegetation cover in relation to climatic factors on the Tibetan Plateau. J Plant Ecol $30: 1-8$

Yang J, Ding Y, Chen R (2005) NDVI relation of alpine vegetation changes in the Source Regions of the Yangtze and Yellow rivers. Acta Geogr Sin 60:467-478

Yang K, Guo X, He J, Qin J, Koike T (2010) On the climatology and trend of the atmospheric heat source over the Tibetan Plateau: an experiments-supported revisit. J Clim 24:1525-1541. doi:10. 1175/2010JCLI3848.1

Yang K, Ye B, Zhou D, Wu B, Foken T, Qin J, Zhou Z (2011) Response of hydrological cycle to recent climate changes in the Tibetan Plateau. Clim Change 109:517-534. doi:10.1007/ s10584-011-0099-4 
Yang K, Wu H, Qin J, Lin C, Tang W, Chen Y (2014) Recent climate changes over the Tibetan Plateau and their impacts on energy and water cycle: a review. Global Planet Change 112:79-91. doi:10.1016/j.gloplacha.2013.12.001

Yu H, Xu J, Okuto E, Luedeling E (2012) Seasonal Response of Grasslands to Climate Change on the Tibetan Plateau. PLoS One 7:e49230. doi:10.1371/journal.pone.0049230

Zhang G, Ouyang H, Zhang X, Zhou C, Xu X (2010) Vegetation change and its responses to climatic variation besed on eco- geographical regions of Tibetan Plateau. Geogr Res 29:2004-2016

Zhang G, Zhang Y, Dong J, Xiao X (2013) Green-up dates in the Tibetan Plateau have continuously advanced from 1982 to 2011. Proc Natl Acad Sci. doi:10.1073/pnas.1210423110

Zhao X, Tan K, Zhao S, Fang J (2011) Changing climate affects vegetation growth in the arid region of the northwestern China. J Arid Environ 75:946-952. doi:10.1016/j.jaridenv.2011.05.007 